\title{
VIEWS AND ANXIETY LEVELS OF TURKISH DENTAL STUDENTS DURING THE COVID-19 PANDEMIC
}

\author{
Melih Özdede', Sezgi Cinel Sahin² \\ 'Department of Dentomaxillofacial Radiology, Faculty of Dentistry, Pamukkale University, Denizli, Turkey \\ ${ }^{2}$ Department of Prosthodontics, Faculty of Dentistry, Pamukkale University, Denizli, Turkey
}

\begin{abstract}
INTRODUCTION: The novel coronavirus disease (COVID-19) has become an important public health problem that may have negative effects on psychological health.

ОвJестIVEs: This study aims to evaluate the views and anxiety levels of dental students during COVID-19.

MATERIAL AND METHODS: A questionnaire consisting of COVID-19 and online education views was filled by the students of a dental faculty. For the determination of the anxiety levels, the participants completed Turkish versions of the state-trait anxiety inventory (STAI) scales. The data was analyzed using descriptive analysis and parametric statistical tests. $P<0.05$ was accepted as significant.

ReSults: A total of 249 dental students (154 females, 95 males), including 143 preclinical and 106 clinical students participated in the survey. Most students (81.1\%) stated that they were concerned that the classes would be held in groups, with the transition to face-to-face education. Most of the participants (69.9\%) stated that the idea of late graduation creates fear. Due to the COVID-19 pandemic, approximately a quarter of the students have the idea of changing professions. The continuity anxiety value of the group with the idea of changing the profession was statistically higher than the other groups $(p<0.05)$.

ConcLusions: The results of our study indicated that dental students in our study were anxious about COVID-19. Our results emphasize the need to create psychological support programs for dental students during and after the pandemic.
\end{abstract}

KEY WORDS: COVID-19, anxiety, dental students, distance learning, psychological stress.

J Stoma 2020; 73, 3: 123-128

DOI: https://doi.org/10.5114/jos.2020.96867

\section{INTRODUCTION}

The novel coronavirus disease COVID-19 was first detected in Wuhan, the capital of Hubei province, China, in December 2019, and it was announced that COVID-19 has become an important public health problem at the international level by the World Health Organization [1-3].
As in the world, serious measures have been taken in Turkey due to high-risk of being infected with this disease. Travel restrictions, quarantine applications, providing social isolation, and closing social areas, such as sports halls, museums, movie theaters, swimming pools, restaurants, and hairdressers, can be counted among these measures [4]. In addition to these precautions, it was recommended that all educational institutions switch

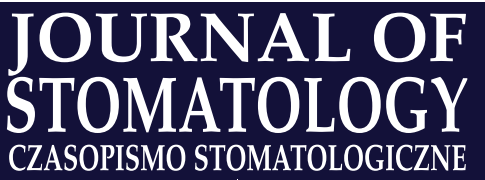
AdDress FOr CORRESPONDENCE: Dr. Melih Ozdede, Department of Dentomaxillofacial Radiology, Faculty of Dentistry, Pamukkale University, Kinikli Campus, TR-20160 Denizli, Turkey, e-mail: melihozdede@gmail.com

RECEIVED: 05.06.2020 • ACCEPTED: 09.06.2020 • PUBLISHED: 30.06.2020 
to online education [5]. In this respect, face-to-face education of dentistry faculties were interrupted, especially due to the education procedures involving the possibility of close contact with symptomatic and asymptomatic COVID-19 patients and the application of aerosol-producing treatment $[4,6]$. It has been announced that teaching at universities in Turkey was suspended two days after the first case of COVID-19 was detected on March 11, 2020. Online theoretic education has started at our university on March 23, 2020 [5].

During the COVID-19 pandemic, online education systems provided advantages such as continuity of education, problem-based learning, and the use of intelligent communication devices and applications; therefore, the students had the opportunity to learn anywhere and anytime. However, from time to time, problems related to universities' digital platforms and interruptions in students' internet access were encountered [7]. At time, the study examining the psychological effects of academic disruptions on students were carried on, it was observed that students' anxiety tendency may have increased, especially due to the interruption of education, which has decreased the motivation about studying. Also, there was a significant potential increase of students' dropout due to the abandonment of daily routines [3, 8-11]. In addition to all these negative factors, it was assumed that the increase of anxiety resulting from the provision of individual safety and preventing the risk of contamination could have negative effects on psychological health of dentistry students $[4,11,12]$.

For the duration of the pandemic, it is particularly important to determine and implement without a delay, all the necessary measures to protect mental health and well-being of dentistry students. It is also important to determine the need for professionally trained counselors, who can understand the psychological status of students $[11,12]$. Until today, numerous scales such as the dental environment stress (DES), Beck depression inventory (BDI), and state-trait anxiety inventory (STAI) have been used to determine the current psychological state [13]. STAI is an important index in determining how the individual feels at a certain moment and under specific conditions (STAI-1), and independently of the situation and conditions (STAI-2) [14]. Also, it offers a more comprehensive assessment due to its content $[13,14]$.

\section{OBJECTIVES}

Although a few studies [15, 16] were performed on medical students regarding COVID-19 stress levels, to the best of our knowledge, no study identifying the stress of dental students during COVID-19 or other pandemic periods was published. The aim of the study was to evaluate the views and anxiety levels of dentistry students during the COVID-19 pandemic.

\section{MATERIAL AND METHODS}

This study was approved by the Ministry of Health, Republic of Turkey (No: 2020-05-20T15_30_12). Ethical approval was received from the Ethics Committee of $\mathrm{Pa}$ mukkale University (No: 60116787-020/31819).

\section{PARTICIPANTS}

The survey was completed by the students of the Pamukkale University, Faculty of Dentistry (Denizli, Turkey). Participation in the survey was voluntary. Demographic information was collected, including age, gender, and year of study. The survey was completed by preclinical (first and second years of study) and clinical years (third and fourth years of study) dental students. Participants who used psychiatric medication in the past year were excluded from the study.

In Turkey, dental education continues for five years. Our faculty began teaching in 2016 in Denizli, Turkey. The current study was carried out among our students studying in the first four years of study, as there are currently no fifth-year students. For this reason, our study was conducted only with the participation of students up to the fourth-year.

\section{SURVEY}

The survey was prepared on an online survey portal (www.surveey.com) and the link was sent to the dental students via smart-phones. An informative text was provided before starting the survey. Only students who voluntarily agreed to participate in the study filled up the survey. The whole survey included two main parts. The questions in the first part were about the views of dental students regarding COVID-19 and tele-education (Table 1). For the second part, STAI scales were used. This inventory was developed by Spielberger et al. [14], with an adaptation of Turkish validity and reliability study performed by Oner and Le Compte [17] consisted of two sub-scales, with each containing 20 questions. The scores obtained from both scales ranged from 20 to 80 . A high score was associated with high anxiety level, while a low score related to low anxiety. The average score level determined in the studies varies between 36 and 41 [18].

All participants completed both general questions and Turkish versions of STAI-1 and STAI-2 scales. The data obtained from the surveys was collected, and statistical analysis was performed.

\section{STATISTICAL ANALYSIS}

Three hundred and sixty students of the Pamukkale University Faculty of Dentistry constituted of the research. 
TABLE 1. The distribution of variables and the comparison with STAI-1 and STAI-2 scales

\begin{tabular}{|c|c|c|c|c|c|c|c|}
\hline \multirow{2}{*}{ Variables } & \multirow{2}{*}{$n(\%)$} & \multicolumn{3}{|c|}{ STAI-1 } & \multicolumn{3}{|c|}{ STAI-2 } \\
\hline & & Mean \pm SD & Min-Max & $p$-value & Mean \pm SD & Min-Max & $p$-value \\
\hline \multicolumn{8}{|l|}{ Gender } \\
\hline Female & $154(61.8)$ & $46.95 \pm 12.07$ & $22-76$ & \multirow{2}{*}{0.845} & $46.25 \pm 9.94$ & $24-71$ & \multirow{2}{*}{0.633} \\
\hline Male & 95 (38.2) & $46.65 \pm 11.47$ & $20-72$ & & $45.65 \pm 8.77$ & $23-65$ & \\
\hline \multicolumn{8}{|l|}{ Level of education } \\
\hline Preclinical & $143(57.4)$ & $46.34 \pm 12.14$ & $20-75$ & \multirow{2}{*}{0.442} & $46.13 \pm 9.43$ & $24-69$ & \multirow{2}{*}{0.839} \\
\hline Clinical & $106(42.6)$ & $47.51 \pm 11.4$ & $24-76$ & & $45.88 \pm 9.64$ & $23-71$ & \\
\hline \multicolumn{8}{|l|}{ Chronic disease } \\
\hline Yes & $14(5.6)$ & $51.5 \pm 15.68$ & $31-76$ & \multirow{2}{*}{0.266} & $46.43 \pm 11.06$ & $32-65$ & \multirow{2}{*}{0.869} \\
\hline No & $235(94.4)$ & $46.56 \pm 11.54$ & $20-75$ & & $46 \pm 9.43$ & $23-71$ & \\
\hline \multicolumn{8}{|l|}{ Following news about COVID-19 } \\
\hline Yes & $194(77.9)$ & $46.78 \pm 11.84$ & $20-76$ & \multirow{3}{*}{0.982} & $46.1 \pm 9.8$ & $23-71$ & \multirow{3}{*}{0.935} \\
\hline Sometimes & $53(21.3)$ & $47.02 \pm 12.07$ & $24-75$ & & $45.79 \pm 8.5$ & $28-63$ & \\
\hline No & $2(0.8)$ & $48 \pm 4.24$ & $45-51$ & & $44 \pm 8.49$ & $38-50$ & \\
\hline \multicolumn{8}{|l|}{ Preference for the education process } \\
\hline Online & $198(79.5)$ & $46.41 \pm 11.66$ & $20-76$ & \multirow{2}{*}{0.259} & $45.52 \pm 9.36$ & $23-68$ & \multirow{2}{*}{0.099} \\
\hline Face-to-face & $51(20.5)$ & $48.51 \pm 12.42$ & $24-75$ & & $47.98 \pm 9.87$ & $30-71$ & \\
\hline \multicolumn{8}{|l|}{ Preference of accommodation } \\
\hline Alone at the student house & $78(31.3)$ & $46.9 \pm 11.51$ & $20-76$ & \multirow{5}{*}{0.435} & $46.92 \pm 9.42$ & $30-71$ & \multirow{5}{*}{0.463} \\
\hline With multiple people at home & $53(21.3)$ & $44.74 \pm 10.39$ & $24-67$ & & $44.28 \pm 9.04$ & $23-68$ & \\
\hline With family & $40(16.1)$ & $46.4 \pm 14.07$ & $23-75$ & & $47 \pm 10.37$ & $24-65$ & \\
\hline State dormitory & $62(24.9)$ & $48.98 \pm 10.76$ & $25-68$ & & $46.24 \pm 8.54$ & $30-66$ & \\
\hline Private dormitory & $16(6.4)$ & $46.31 \pm 15.32$ & $22-73$ & & $44.06 \pm 12.47$ & $26-69$ & \\
\hline \multicolumn{8}{|l|}{ Collective group lesson anxiety } \\
\hline Yes & $202(81.1)$ & $46.76 \pm 12.09$ & $20-76$ & \multirow{3}{*}{0.863} & $46.14 \pm 9.74$ & $24-71$ & \multirow{3}{*}{0.913} \\
\hline Not sure & $22(8.8)$ & $48.09 \pm 11.11$ & $24-67$ & & $45.32 \pm 9.82$ & $23-67$ & \\
\hline No & $25(10.0)$ & $46.36 \pm 10.54$ & $30-68$ & & $45.68 \pm 7.29$ & $33-60$ & \\
\hline Taking individual protective measur & classes & & & & & & \\
\hline Yes & $214(85.9)$ & $46.4 \pm 11.96$ & $20-76$ & & $45.85 \pm 9.69$ & $23-71$ & \\
\hline Not sure & $29(11.6)$ & $50.28 \pm 11.03$ & $30-71$ & 0.249 & $47.79 \pm 8.18$ & $26-59$ & 0.486 \\
\hline № & $6(2.4)$ & $45.83 \pm 9.02$ & $30-58$ & & $43.67 \pm 8.59$ & $28-52$ & \\
\hline Fear of late graduation & & & & & & & \\
\hline Yes & $174(69.9)$ & $46.67 \pm 12.1$ & $20-76$ & & $46.02 \pm 9.64$ & $24-71$ & \\
\hline Not sure & $27(10.8)$ & $49.19 \pm 12.78$ & $23-71$ & 0.533 & $49.04 \pm 8.19$ & $33-59$ & 0.120 \\
\hline No & $48(19.3)$ & $46.15 \pm 10.23$ & $24-69$ & & $44.33 \pm 9.43$ & $23-64$ & \\
\hline The idea of changing the profession & & & & & & & \\
\hline Yes & $39(15.7)$ & $49.79 \pm 9.84$ & $30-67$ & & $49.62 \pm 9.27$ & $30-69$ & \\
\hline Not sure & $22(8.8)$ & $48.68 \pm 11.56$ & $31-68$ & 0.143 & $46.36 \pm 8.45$ & $31-59$ & $0.031^{*}$ \\
\hline No & $188(75.5)$ & $46.01 \pm 12.16$ & $20-76$ & & $45.23 \pm 9.53$ & $23-71$ & \\
\hline
\end{tabular}

$S D$ - standard deviation, STAI - state-trait anxiety inventory, Student's t-test, One-way ANOVA test * $p<0.05$ 
For the 95\% confidence interval (t: 1.96), when the frequency of view of the examination was taken as 0.05 , and the accepted sampling error was 0.05 , the number of samples calculated according to the formula below was 186 [19]:

$$
n=\frac{N t^{2} p q}{d^{2}(N-1)+t^{2} p q}
$$

NCSS (number cruncher statistical system) 2007 (Kaysville, Utah, USA) program was used for statistical analysis. The data was evaluated by descriptive statistical. The distribution of data was evaluated with Shapiro-Wilk test. ANOVA was used for the comparison of three or more groups with normal distribution of quantitative data, and post-hoc tests were used to determine the differences. Student's $t$-test was used to compare two groups with normal distribution of quantitative data. Statistical significance was estimated at $p<0.01$ and $p<0.05$.

\section{RESULTS}

A total of 249 dental students (154 females, 95 males), including 143 preclinical (first and second year of study) and 106 clinical students (third and fourth-year of study) participated in the survey (Table 1 ). The response rate was $69.2 \%$. Percentages of participation were $29.1 \%, 28.7 \%$, $21.5 \%, 20.7 \%$ for first and fourth-year of study, respectively. The age range of the participants ranged from 18 to 24 , with a mean of $20.7 \pm 1.4$.

The majority of the participants did not have a chronic disease and followed the news about COVID-19. Most of respondents stated that they prefer online education. One-third of the participants indicated that they plan to stay alone at the student house after the COVID-19 period. The vast majority of the students confirmed that they are concerned about the classes held in groups, with the transition to face-to-face education. Details are shown in Table 1.

With the normalization of the COVID-19, 83.9\% $(n=209)$ of the participants indicated that they consider the dining halls risky after the pandemic, $13.7 \%(n=34)$ were not sure about this issue, and $2.4 \%$ of them $(n=6)$ did not find it risky.

Most of the participants would prefer to use personal protective equipment in classes (Table 1). On a question regarding the type of protective measures during the lessons, $41.4 \%(n=103)$ of the students responded that they would use masks, shields, and gloves, $38.6 \%(n=96)$ would use masks, visors, gloves, and disposable gowns, $14.5 \%(n=36)$ would use masks only, $4.4 \%(n=11)$ would use masks and shields, and $1.2 \%(n=3)$ would use shields only.

Most of the participants (69.9\%) stated that the idea of late graduation created anxiety. Due to the COVID-19 pandemic, it is noteworthy that approximately a quarter of the students had the idea of changing the profession (Table 1).
Table 1 presents the comparison of the variables and STAI scales. When comparing the variables according to STAI-1, the average of the scale with any variable was not statistically significant $(p>0.05)$. On the other hand, according to the STAI-2 scale, the mean of the scale showed a statistically significant difference only in the variable, in which the idea of changing the profession was indicated $(p=0.031, p<0.05)$. The continuity anxiety value of the group with the idea of changing the profession was higher than the group that have not thought of changing the profession $(p=0.026, p<0.05)$.

\section{DISCUSSION}

Dentistry is considered an extremely stressful profession. Education life is also demanding, as it is a period that requires intensive theoretical knowledge along with interpersonal communication skills and clinical abilities [20, 21]. In previous studies, it has been reported that the stress in dentistry students varied according to ethnic differences, gender, and year of study [13].

The COVID-19 pandemic has been affecting lives of many people worldwide. The rapid increase in the number of infected cases preceded to increased feelings of uncertainty and anxiety in humans. Disruption in education and other issues also caused anxiety among university students [15]. Increased stress level in students can lead to lack of concentration and deterioration of their psychological states [8]. Students returning to their homes because of the closure of the universities are worried about not being able to return to their schools. The measures taken by universities to support the mental state of students are uncertain [8]. Our study aimed to evaluate the current psychological states of dental students during the COVID-19 period.

Stress levels of dental students were evaluated by using various scales, including STAI, DES, BDI, depression, anxiety and stress scale (DASS), Maslach burnout inventory (MBI), psychosocial stress inventory (PSSI), brief symptom inventory (BSI), generalized anxiety disorder (GAD), and psychological general well-being (PGWB) $[13,22-26]$. STAI-1 scale aims to determine the persistent anxiety of a person, while STAI-2 aims to assess the continuity of anxiety [13]. In the current study, we preferred STAI scales because they allow both a certain time and a long time to be evaluated and are more appropriate for periods with psychological variations, such as pandemics.

In the literature, there are studies, in which stress levels of medical students are measured after pandemics that have appeared before [26, 27]. Loh et al. [27] evaluated the knowledge and anxiety of medical students during severe acute respiratory syndrome (SARS) outbreak in 2003. The researchers reported that junior medical students expressed higher anxiety levels, compared to senior medical students [27]. In our COVID-19 study, no statistical differences were found between the education level and anxiety. 
Al-Rabiaah et al. [26] investigated the stresses of medical students in the Middle East during respiratory syndrome-related coronavirus (MERS-CoV) outbreak, which occurred in 2014. According to that study, about a quarter of medical students have been reported to be affected by mild to moderate anxiety [26]. Moreover, the researchers found that females students had statistically higher stress levels than males; however, no differences were observed between education levels. The only study evaluating the anxiety levels of medical students in the COVID-19 pandemic was performed by Cao et al. [16]. In this study, $21.3 \%$ of the medical students presented mild, $2.7 \%$ of them showed moderate, and $0.9 \%$ of them had severe anxiety levels. Similar to previous studies, it was determined that the students in our study were anxious about pandemic $[15,16,26]$. On the other hand, there was no statistical difference between gender and anxiety levels in our study, which corresponded to results of Cao et al. [16] but contrasted with the study of AlRabiaah et al. [26].

The only study evaluating the views of medical students during COVID-19 outbreak was performed by Aker and Midik [15]. In this study, serious issues regarding COVID-19 pandemic, in which medical students were most interested were investigated, and the question of "how/when the pandemic will come to end" was at the top of the most interested topics (42.9\%). The effect of COVID-19 on education was the most concerned subject for only $4.5 \%$ of students. Furthermore, more than half of the participants indicated that they were mentally poor [15]. In our study, dental students' anxiety levels were questioned and their anxiety in education-related issues was found to be high. The high level of anxiety in dental students was thought to be associated with the high-risk of cross-contamination caused by aerosols during dental procedures and close contact with patients $[4,6]$. In our study, the results of students preferring online education rather than face-to-face education, and that most of them will pay attention to personal protective measures, support this situation. Additionally, it was determined that a group of dental students considered changing their professions because of high-risk of infection in dental procedures, and their continuity anxiety levels (STAI-2) were higher than other students $(p<0.05)$.

Among the limitations of our study, as in other cross-sectional studies, our results demonstrate a certain period of the pandemic. Moreover, as this study includes students from one dental faculty, these results may vary in other faculties and/or other countries. New studies are recommended at different phases of pandemics, in different countries, and with bigger number of participants.

\section{CONCLUSIONS}

The results of our study indicated that dental students were anxious about the COVID-19 pandemic.
The severity of the mental health of dentistry students should be determined with detailed analysis. It should be emphasized that universities should establish crisis-oriented psychological support programs for dentistry students during a pandemic and cooperate with other public institutions in this sense. Dentistry faculties need to reconsider training and infection protocols, so that students can spend this period during the unexpected pandemic without interrupting their education and suffering psychological concern.

\section{ACKNOWLEDGEMENTS}

We would like to thank Hande Emir for the statistical analyses.

\section{CONFLICT OF INTEREST}

The authors declare no potential conflicts of interest with respect to the research, authorship, and/or publication of this article.

\section{References}

1. Zhu N, Zhang D, Wang W, et al. A novel coronavirus from patients with pneumonia in China, 2019. N Engl J Med 2020; 382: 727-733.

2. Mahase E. China coronavirus: WHO declares international emergency as death toll exceeds 200. BMJ 2020; 368: m408.

3. Wang C, Horby PW, Hayden FG, et al. A novel coronavirus outbreak of global health concern. Lancet 2020; 395: 470-473.

4. Peker İ, Pamukçu U, Taka K, Üçok Ö. Diş hekimliği pratiğinde Koronavirüs salgınına karşı alınması gereken önlemler. Turkiye Klin J Dent Sci 2020; doi: 10.5336/dentalsci.2020-75270.

5. PAU. Dersler dijital ortamda işlenmeye başliyor [Internet]. Available from: http://www.pau.edu.tr/pau/tr/duyuru/dersler-dijitalortamda-islenmeye-basliyor (Accessed: 22.05.2020).

6. Peker İ, Özdede M. İntraoral dijital görüntülemede enfeksiyon kontrolü. Turkiye Klin J Oral Maxillofac Radiol-Special Top 2016; 2: 55-60.

7. Meng L, Hua F, Bian Z. Coronavirus disease 2019 (COVID-19): emerging and future challenges for dental and oral medicine. J Dent Res 2020; 99: 481-487.

8. Sahu P. Closure of universities due to Coronavirus disease 2019 (COVID-19): Impact on education and mental health of students and academic staff. Cureus 2020; 12: e7541.

9. Torales J, O'Higgins M, Castaldelli-Maia JM, Ventriglio A. The outbreak of COVID-19 coronavirus and its impact on global mental health. Int J Soc Psychiatry 2020; 66: 317-320.

10. Grubic N, Badovinac S, Johri AM. Student mental health in the midst of the COVID-19 pandemic: a call for further research and immediate solutions. Int J Soc Psychiatry 2020; doi: 10.1177/ 0020764020925108.

11. Iyer P, Aziz K, Ojcius DM. Impact of COVID-19 on dental education in the United States. J Dent Educ 2020; doi: 10.1002/jdd. 12163.

12. Zhai Y, Du X. Mental health care for international Chinese students affected by the COVID-19 outbreak. Lancet Psychiatry 2020; 7: e22.

13. Peker I, Toraman Alkurt M, Usta MG, Turkbay T. The evaluation of perceived sources of stress and stress levels among Turkish dental students. Int Dent J 2009; 59: 103-111. 
14. Spielberger CD, Gorsuch RL, Lusahene RE, et al. Manual for the state-trait anxiety inventory. $1^{\text {st }}$ ed. Palo Alto: Consulting Psychologists Press; 1983; 1-36.

15. Aker S, Midik Ö. The views of medical faculty students in Turkey concerning the COVID-19 pandemic. J Community Health 2020; doi: 10.1007/s10900-020-00841-9.

16. Cao W, Fang Z, Hou G, et al. The psychological impact of the COVID-19 epidemic on college students in China. Psychiatry Res 2020; 287: 112934.

17. Oner N, Le Compte A. Süreksiz durumluk sürekli kaygı envanteri el kitabı. $1^{\text {st }}$ ed. Istanbul: Bogazici Universitesi Matbaası; 1983; 1-26 [In Turkish].

18. Bulut E, Poyrazoglu E, Bek Y. Ondokuz Mayıs Üniversitesi Dis Hekimliği Fakültesi öğrencilerinde dental anksiyetenin incelenmesi. Ondokuz Mayıs Univ Dis Hekim Fak Der 2009; 10: 16-24.

19. Asan K. Araştırma evreni ve örneklem. MSc. theses, Dumlupınar University, Kutahya, 2015.

20. Polychronopoulou A, Divaris K. Perceived sources of stress among Greek dental students. J Dent Educ 2005; 69: 682-692.

21. Sanders AE, Lushington K. Effect of perceived stress on student performance in dental school. J Dent Educ 2002; 66: 75-81.

22. Naidu RS, Adams JS, Simeon D, Persad S. Sources of stress and psychological disturbance among dental students in the West Indies. J Dent Educ 2002; 66: 1021-1030.

23. Pohlmann K, Jonas I, Ruf S, et al. Stress, burnout and health in the clinical period of dental education. Eur J Dent Educ 2005; 9: 78-84.

24. Sugiura G, Shinada K, Kawaguchi Y. Psychological well-being and perceptions of stress amongst Japanese dental students. Eur J Dent Educ 2005; 9: 17-25.

25. Basudan S, Binanzan N, Alhassan A. Depression, anxiety and stress in dental students. Int J Med Educ 2017; 8: 179-86.

26. Al-Rabiaah A, Temsah MH, Al-Eyadhy AA, et al. Middle East Respiratory Syndrome-Corona Virus (MERS-CoV) associated stress among medical students at a university teaching hospital in Saudi Arabia. J Infect Public Health 2020; 13: 687-691.

27. Loh LC, Mohd Ali A, Ang TH, Chelliah A. Impact of a spreading epidemic on medical students. Malaysian J Med Sci 2006; 13: 30-36. 